\title{
Precipitation Extremes Estimated by GPCP and TRMM: ENSO Relationships
}

\author{
SCOTT CuRTIS \\ Atmospheric Science Laboratory, Department of Geography, East Carolina University, Greenville, North Carolina
}

Ahmed Salahuddin

Coastal Resources Management, Atmospheric Science Laboratory, Department of Geography, East Carolina University, Greenville, North Carolina

Robert F. AdLER

NASA Goddard Space Flight Center, Greenbelt, Maryland

George J. HufFman

Science Systems and Applications, Inc., NASA Goddard Space Flight Center, Greenbelt, Maryland

GuOJun Gu AND YANG Hong

Goddard Earth Science and Technology Center, NASA Goddard Space Flight Center, Greenbelt, Maryland

(Manuscript received 10 April 2006, in final form 20 December 2006)

ABSTRACT

\begin{abstract}
Global monthly and daily precipitation extremes are examined in relation to the El Niño-Southern Oscillation phenomenon. For each month around the annual cycle and in each $2.5^{\circ}$ grid block, extremes in the Global Precipitation Climatology Project dataset are defined as the top five (wet) and bottom five (dry) mean rain rates from 1979 to 2004. Over the tropical oceans El Niño-Southern Oscillation events result in a spatial redistribution and overall increase in extremes. Restricting the analysis to land shows that El Niño is associated with an increase in frequency of dry extremes and a decrease in wet extremes resulting in no change in net extreme months. During La Niña an increase in frequency of dry extremes and no change in wet extremes are observed. Thus, because of the juxtaposition of tropical land areas with the ascending branches of the global Walker Circulation, El Niño (La Niña) contributes to generally dry (wet) conditions in these land areas.

In addition, daily rain rates computed from the Tropical Rainfall Measuring Mission Multisatellite Precipitation Analysis are used to define extreme precipitation frequency locally as the number of days within a given season that exceeded the 95th percentile of daily rainfall for all seasons (1998-2005). During this period, the significant relationships between extreme daily precipitation frequency and Niño-3.4 in the Tropics are spatially similar to the significant relationships between seasonal mean rainfall and Niño-3.4. However, to address the shortness of the record extreme daily precipitation frequency is also related to seasonal rainfall for the purpose of identifying regions where positive seasonal rainfall anomalies can be used as proxies for extreme events. Finally, the longer (1979-2005) but coarser Global Precipitation Climatology Project analysis is reexamined to pinpoint regions likely to experience an increase in extreme precipitation during El Niño-Southern Oscillation events. Given the significance of El Niño-Southern Oscillation predictions, this information will enable the efficient use of resources in preparing for and mitigating the adverse effects of extreme precipitation.
\end{abstract}

\section{Introduction}

A current focus of the Global Water and Energy Cycle Experiment (GEWEX) is extreme precipitation

Corresponding author address: Dr. Scott Curtis, Atmospheric Science Laboratory, Department of Geography, East Carolina University, Brewster A232, Greenville, NC 27858.

E-mail: curtisw@ecu.edu
(Stewart 2005), which is defined as an anomalous deficit of rainfall over a period of months and excessive rains from hours to months. The result can be drought and flood respectively, with each having important socioeconomic consequences. Extreme precipitation events are fundamental features of the climate system (Stewart 2005), but a clear understanding of how extreme events change in intensity and frequency during periods of extreme climate variability is lacking.

DOI: 10.1175/JHM601.1

(C) 2007 American Meteorological Society 
One possible change in the probability density function (PDF) of monthly rainfall, given a warming climate, is an increase in variance with little change in the mean (Katz and Brown 1992). In fact, there is no significant change in mean global rainfall since 1979 according to the Global Precipitation Climatology Project (GPCP) product (Adler et al. 2003a; Gu et al. 2007). Over land, the Intergovernmental Panel on Climate Change (IPCC; Houghton et al. 2001) reports a 5\%$10 \%$ increase in precipitation in the Northern Hemisphere since 1900, with much of the trend due to intense rainfall. In that regard, modeling studies show an increase in extreme precipitation for most of the globe using IPCC projections of carbon dioxide and aerosol concentrations (Kharin and Zwiers 2000). Easterling et al. (2000) report an increase in the upper fifith percentile of observed precipitation for the United States and other countries since the 1930s, and the tendency for an increase in seasonal rainfall to be directly related to an increase in the amount of precipitation falling during extreme events. However, these results are restricted to those countries with high-quality long-term data, which limits a truly global observational analysis. Satellite datasets provide global coverage, but are far too short to be used for trend analyses, and are often too coarse in time and space to capture extremes. However, the Tropical Rainfall Measuring Mission (TRMM) is now being used to describe extreme events (Zipser et al. 2006), and TRMM is beginning to appear in interannual climate studies, such as in describing El NiñoSouthern Oscillation (ENSO; Haddad et al. 2004).

The ENSO phenomenon causes global temperature change and thus may be helpful in examining how precipitation extremes respond to a changing climate. In fact, recent studies examining long-term datasets of extreme precipitation in South America (Haylock et al. 2006) and South Africa (Fauchereau et al. 2003) reveal that increasing trends in the frequency and severity of daily rainfall and drought can partially be explained by a shift to ENSO-dominant conditions in the late twentieth century.

There is a well-recognized relationship between seasonal rainfall and ENSO (e.g., Ropelewski and Halpert 1987, 1989), but only recently has there been an attempt to relate ENSO to extreme precipitation events at the daily scale. Gershunov and Barnett (1998) using the 75th percentile of daily rainfall to indicate frequency of heavy events, found ENSO signals in the Southeast, Gulf Coast, central Rockies, and the general area of the Mississippi-Ohio River valleys. In addition, ENSO appears to influence extreme events at the south coast of Alaska (L'Heureux et al. 2004). The predictive skill of extreme precipitation over the contiguous United
States is mostly attributed to ENSO (Gershunov and Cayan 2003). Cavazos and Rivas (2004) found that ENSO explains $36 \%$ of the interannual variability in 1-day extreme precipitation frequency in Tijuana, Mexico. A trough in the subtropical jet, a warm California Current off Baja California, Mexico, and lowlevel moisture advection feed convective activity in the region (Cavazos and Rivas 2004). Extreme precipitation in São Paulo, Brazil, is related to warm ENSO events, which favor a persistent oceanic South Atlantic convergence zone (Liebmann et al. 2001; Carvalho et al. 2002, 2004).

Studies have also analyzed the effect of ENSO on the frequency and severity of monthly extreme precipitation integrated over all land areas. Dai et al. (1997) found that ENSO is the single largest cause of global extreme precipitation events over land. Goddard and Dilley (2005), however, found that monthly precipitation extremes are not well related to ENSO over tropical land areas as a whole. Curtis et al. (2006) argue that Goddard and Dilley's (2005) parametric model of the PDF of monthly rainfall is inadequate for evaluating extremes, and present an alternative methodology that yields a stronger relationship between precipitation extremes and El Niño. Interestingly, Lyon and Barnston (2005), using a similar index to the one used by Goddard and Dilley (2005) except with a weighting to dampen large normalized anomalies at the beginning and end of dry seasons, show that the spatial extent of very wet and dry months in tropical land areas increases with extreme La Niña and El Niño, respectively. While the analysis over land is important in its own right, one must not forget that the water cycle is a global system, and climate variations of precipitation extremes must be quantified over ocean as well. In this paper we define precipitation extremes locally over both land and ocean on both monthly and daily time scales with merged satellite products, to help answer the following question: "Is ENSO related to a greater number of precipitation extremes globally and/or regionally?"

\section{Data and methodology}

GPCP, under the World Climate Research Program (WRCP) and GEWEX, provides community global precipitation products with satellite and gauge information at the daily (Huffman et al. 2001), pentad (Xie et al. 2003), and monthly (Adler et al. 2003a) time scales. The GPCP monthly product is used to compute an index of fractional area covered by extreme monthly precipitation $\left(\mathrm{FC}_{\mathrm{p}}\right)$. At each $2.5^{\circ}$ latitude $\times 2.5^{\circ}$ longitude grid block and for the 12 calendar months precipitation was ranked from 1979 to 2004, following Curtis et al. (2006). The top five and bottom five of the $26 \mathrm{yr}$, 
TABLE 1. Mean and std dev of $\mathrm{FC}_{\mathrm{p} 0.38}(\%)$ over the globe and deep Tropics for land, ocean, and total.

\begin{tabular}{|c|c|c|c|c|c|}
\hline & & $\begin{array}{c}\mathrm{FC}_{\mathrm{p} 0.38} \text { mean } \\
1979-\text { Jun } 1987+ \\
\text { Dec } 1987\end{array}$ & $\begin{array}{c}\mathrm{FC}_{\mathrm{p} 0.38} \text { std dev } \\
1979-\text { Jun } 1987+ \\
\text { Dec } 1987\end{array}$ & $\begin{array}{c}\mathrm{FC}_{\mathrm{p} 0.38} \text { mean } \\
\text { Jul } 1987-2004- \\
\text { Dec } 1987\end{array}$ & $\begin{array}{c}\mathrm{FC}_{\mathrm{p} 0.38} \text { std dev } \\
\text { Jul } 1987-2004- \\
\text { Dec } 1987\end{array}$ \\
\hline \multirow[t]{3}{*}{ Globe $\left(67.5^{\circ} \mathrm{N}-85^{\circ} \mathrm{S}\right)$} & Ocean & 25.3 & 4.6 & 45.0 & 3.5 \\
\hline & Land & 37.6 & 4.1 & 38.9 & 3.6 \\
\hline & Total & 29.1 & 3.8 & 43.1 & 3.1 \\
\hline \multirow[t]{3}{*}{ Tropics $\left(25^{\circ} \mathrm{N}-25^{\circ} \mathrm{S}\right)$} & Ocean & 32.5 & 7.3 & 41.4 & 5.6 \\
\hline & Land & 39.5 & 6.2 & 38.0 & 5.8 \\
\hline & Total & 34.4 & 6.1 & 40.5 & 4.9 \\
\hline
\end{tabular}

amounting to approximately the 81 st and 19 th percentiles, were retained. The definition of "extreme" here is rather generous, but chosen to satisfy sampling issues. The chosen thresholds are equivalent to \pm 1 standard deviations from the mean if one assumes normality. Rainfall anomalies in excess of these levels have been used in previous studies to focus on the severity of extreme anomalies (Goddard and Dilley 2005). For each year and month the fractional coverage of the globe falling outside those percentiles, amounting to $38 \%$ of the precipitation values, was calculated $\left(\mathrm{FC}_{\mathrm{p} 0.38}\right)$. Very arid regions were not included, namely, locations with a monthly median rainfall of zero.

Next, $\mathrm{FC}_{\mathrm{p} 0.38}$ was calculated separately for the globe $\left(67.5^{\circ} \mathrm{N}\right.$ to $\left.85^{\circ} \mathrm{S}\right)$, Northern Hemisphere extratropics $\left(67.5^{\circ}\right.$ to $\left.25^{\circ} \mathrm{N}\right)$, Southern Hemisphere extratropics $\left(25^{\circ}\right.$ to $\left.67.5^{\circ} \mathrm{S}\right)$, and Tropics $\left(25^{\circ} \mathrm{N}\right.$ to $\left.25^{\circ} \mathrm{S}\right)$ over ocean, land, and all $2.5^{\circ}$ grid blocks. The global analysis is somewhat restricted in terms of latitude extent, due to incomplete data records in the polar zones. The final $\mathrm{FC}_{\mathrm{p} 0.38}$ values were produced by normalizing the 12 time series over two different periods to address the inhomogeneity in the spatial variability of the GPCP record (Adler et al. 2003a). For the period January 1979 to June 1987 plus December 1987 the multisatellite GPCP product is determined by the outgoing longwave radiation (OLR) precipitation index (OPI; Xie and Arkin 1998). For the remainder of the months the multisatellite product is determined by Special Sensor Microwave Imager (SSM/I)-based precipitation estimates (Wilheit et al. 1991). The inhomogeneity does not appear to affect the time trend of the global mean GPCP precipitation, but somewhat affects the probability density function $(\mathrm{Gu}$ et al. 2007) due to the greater spatial smoothness of the fields in the earlier period. Table 1 shows the mean and standard deviations used to normalize $\mathrm{FC}_{\mathrm{p} 0.38}$ over the globe and Tropics for the two periods in question. In all cases the probability density functions for the two periods are significantly different according to a Kolmogorov-Smirnov test (1\% level for all except tropical land which is significant at the $5 \%$ level). The largest difference between the two time periods is over the global oceans, where the coverage by extreme events is greater during the SSM/I era. The microwave radiometer detects emissions from hydrometeors, which is better related to rainfall than cloud-top properties on which the OPI depends.

To determine the frequency of extreme events over a season, daily precipitation averages were calculated from TRMM Multisatellite Precipitation Analysis (TMPA; TRMM standard product number 3B42, version 6; Huffman et al. 2007). The TMPA has a nominal resolution of $3 \mathrm{~h}$ and extends from 1 January 1998 to the near present. The TMPA algorithm uses the TRMM Combined Instrument (TRMM Precipitation Radar and TRMM Microwave Imager) dataset to calibrate precipitation estimates derived from the available passive microwave radiometers and then merges all these estimates at 3-h intervals. Gaps in these analyses are filled using geosynchronous infrared data regionally calibrated to the merged microwave product. Finally, each 3-hourly field is rescaled to a monthly satellitegauge combination precipitation estimate (Huffman et al. 2007). The dataset is gridded at a $0.25^{\circ}$ latitude $\times$ $0.25^{\circ}$ longitude resolution and extends from $50^{\circ} \mathrm{N}$ to $50^{\circ} \mathrm{S}$. Here we restrict our analysis to the TRMM domain $\left(35^{\circ} \mathrm{N}\right.$ to $\left.35^{\circ} \mathrm{S}\right)$. Extreme precipitation frequency was determined within a season to account for regions of strong annual variability in rainfall like the monsoons. Seasons were defined as January-March (JFM), April-June (AMJ), July-September (JAS), and October-December (OND). Extreme precipitation frequency was defined for each $0.25^{\circ}$ grid block as the number of days within a given season that exceeded the 95th percentile of daily rainfall for all eight seasons from 1998 to 2005 . Thus, if the top $5 \%$ of days were distributed evenly over all years, each season would have 4-5 days of extreme precipitation. The percentage of seasonal precipitation falling on days with rainfall in excess of the 95th percentile is considered a sufficient indicator of extremes, and is easy to calculate and interpret (Nicholls and Murray 1999). More stringent thresholds were also examined and found not to change the results considerably. 


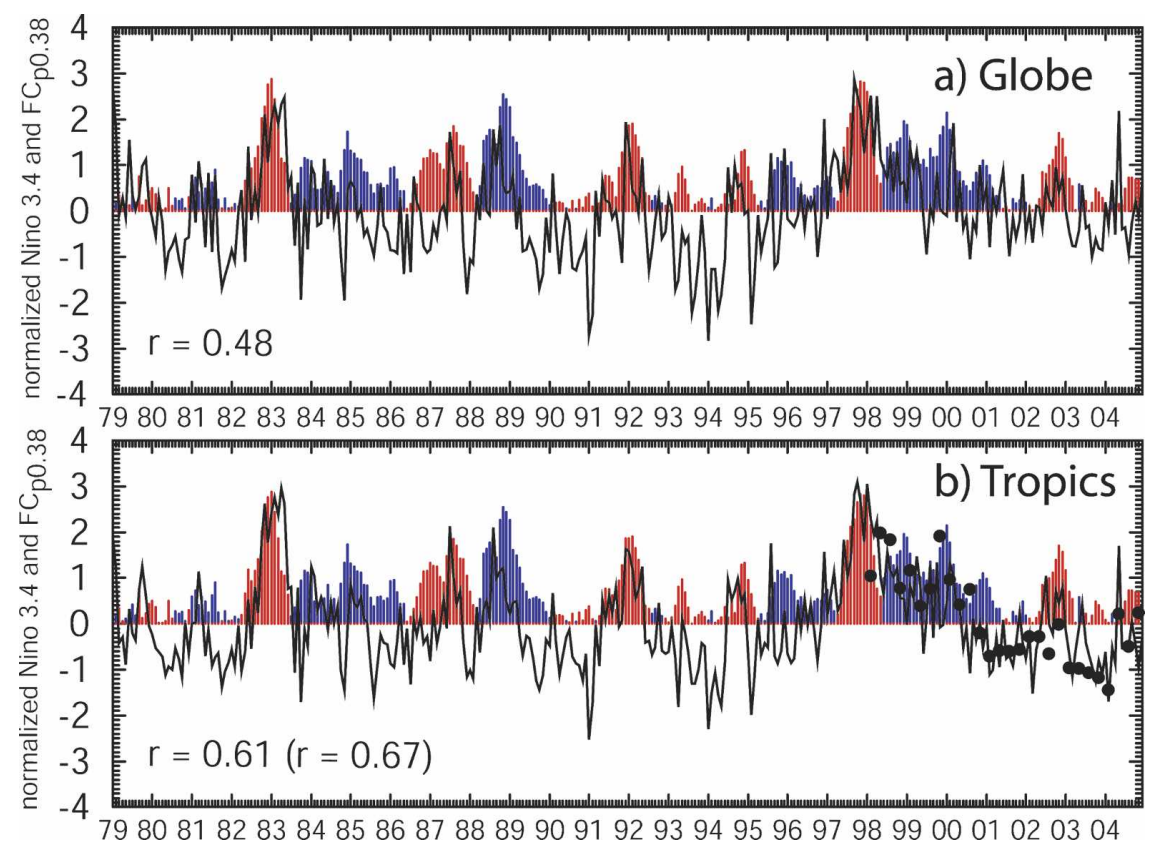

FIG. 1. The relation between ENSO strength and fractional coverage of monthly extreme precipitation integrated over the (a) globe $\left(67.5^{\circ} \mathrm{N}-85^{\circ} \mathrm{S}\right)$ and (b) Tropics $\left(25^{\circ} \mathrm{N}-25^{\circ} \mathrm{S}\right)$ from 1979 to 2004 in the GPCP dataset. Bars are the absolute value of normalized Niño-3.4 with red indicating positive (in the direction of El Niño) and blue negative (in the direction of La Niña) values. Curves denote $\mathrm{FC}_{\mathrm{p} 0.38}$. Monthly correlations are given as the $r$ values without parentheses. Closed circles in (b) represent the normalized area-averaged number of extreme days in each season for the TMPA. Correlation with seasonal Niño-3.4 is within the parentheses.

The Niño-3.4 region $\left(5^{\circ} \mathrm{S}-5^{\circ} \mathrm{N}, 160^{\circ} \mathrm{E}-150^{\circ} \mathrm{W}\right) \mathrm{SST}$ anomaly index was used to define the strength of ENSO and identify individual El Niño and La Niña events. Niño-3.4 is generally the preferred index of ENSO when examining the widespread global effects of ENSO (Trenberth 1997). Niño-3.4 was normalized over the entire record for the monthly analysis (section 3a) and seasonally for the daily analysis (section 3b). For determining relationships involving frequency data at the $0.25^{\circ}$ grid block resolution, we chose Kendall's $\tau$ nonparametric test. Kendall's $\tau$ is similar to Spearman's rank order correlation, but uses the relative ordering of ranks instead of the numerical difference in ranks. For all other relationships we used Pearsons's correlation. Correlations of monthly time series were adjusted by a 3-month autocorrelation to account for the reduction of effective number of degrees of freedom due to persistence Bartlett (1935).

\section{Results}

\section{a. Monthly precipitation extremes}

Since previous studies would suggest that extreme monthly precipitation frequency would increase for both El Niño and La Niña, $\mathrm{FC}_{\mathrm{p} 0.38}$ and the absolute value of Niño-3.4 were plotted together from 1979 to 2004 (Fig. 1). While there is some obvious noise in the $\mathrm{FC}_{\mathrm{p} 0.38}$ time series, overall during both El Niño and La Niña events the fractional coverage of extreme monthly precipitation over the globe is higher than the mean. The fractional coverage dips below the mean during neutral periods, such as 1993 and 1994 (Fig. 1a). Even with the noise, the correlation between the two time series is 0.48 , significant at the $1 \%$ level. Performing the analysis separately on the Northern and Southern Hemispheres yields insignificant correlations. However, the correlation between the absolute value of Niño-3.4 and $\mathrm{FC}_{\mathrm{p} 0.38}$ within the Tropics (Fig. 1b) is improved $(r=0.61)$ compared to the globe as a whole. In fact, the global and Tropics-only $\mathrm{FC}_{\mathrm{p} 0.38}$ time series are very similar $(r=0.87)$, suggesting strong spatial correlation between ENSO and monthly precipitation extremes in the Tropics. Thus, the ENSO signal in global monthly precipitation extremes appears to be controlled by climate variations in the Tropics.

Furthermore, tropical monthly precipitation extremes are largely controlled by changes over the ocean. Figure 2 divides the data from Fig. $1 \mathrm{~b}$ into wet 

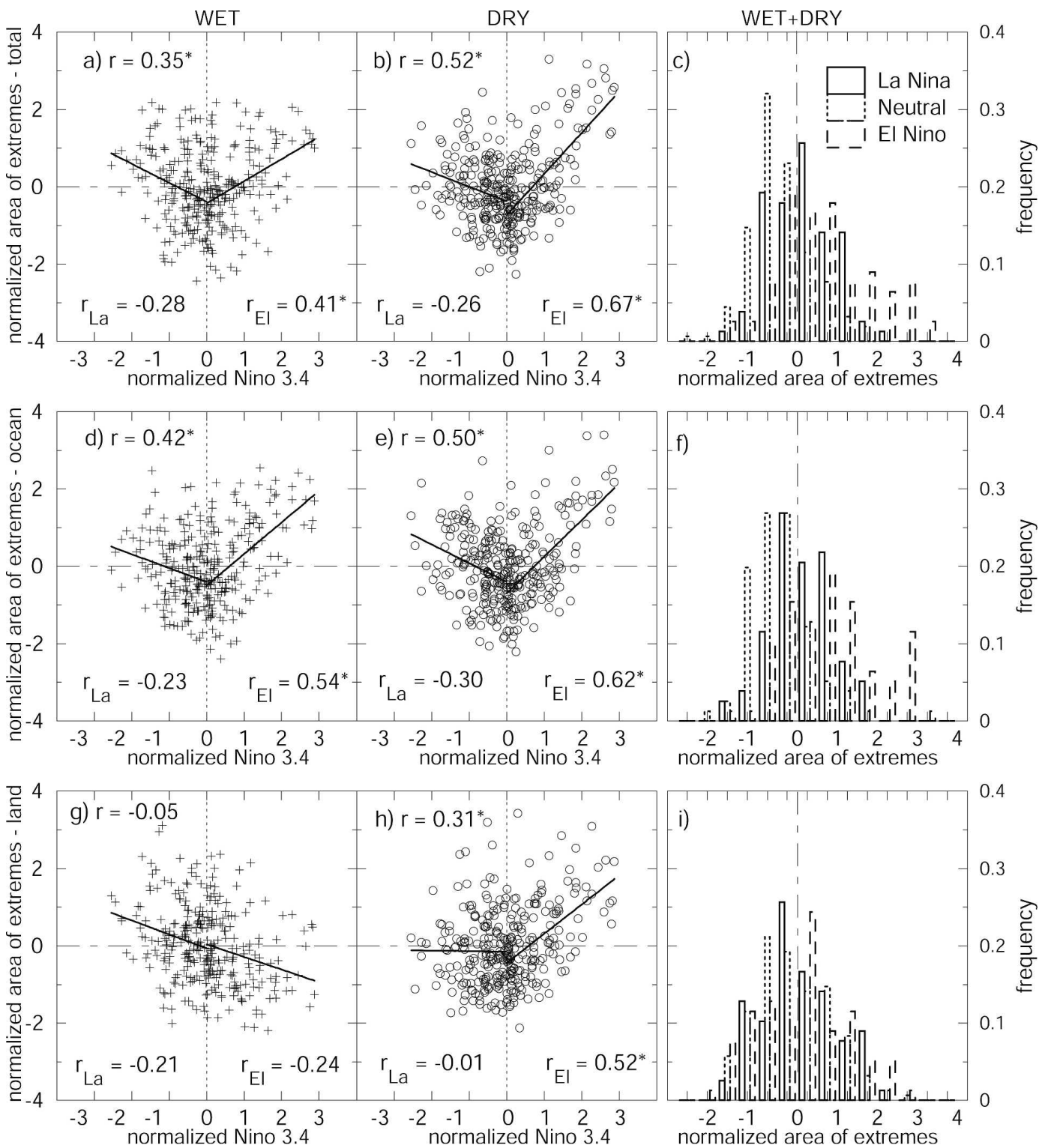

FIG. 2. Scatterplots and histograms of normalized spatial extent of monthly extreme precipitation in the deep Tropics as a function of normalized Niño-3.4: (a) wet and (b) dry extremes. Linear least squares curves are plotted and correlations are given for Niño-3.4 $>0.0\left(r_{\mathrm{El}}\right)$ and Niño-3.4 $<0.0\left(r_{\mathrm{La}}\right)$. The $r$ denotes the correlation between the area of extremes and the absolute value of Niño-3.4. Asterisks denote significance at the $1 \%$ level. (c) Frequency histogram of the normalized area of wet plus dry extremes for El Niño (top quarter of Niño-3.4), La Niña (bottom quarter of Niño-3.4), and neutral (middle half of Niño-3.4). (d)-(f) Same as in (a)-(c), except for ocean only. (g)-(i) Same as in (a)-(c), except for land only.

and dry extremes over ocean and land. For the Tropics as a whole scatterplots of the spatial extent of dry and wet extremes with Niño-3.4 form a v-shaped pattern (marked by two best-fit lines for Niño $3.4>$ and $<0$ ), and thus both tails of the distribution of rainfall contribute similarly to the large correlation between $\mathrm{FC}_{\mathrm{p} 0.38}$ and the absolute value of Niño-3.4 (Fig. 1b). In other words, the spatial extent of wet and dry extremes increases (Figs. 2a,b) with ENSO. We also examined the frequency distribution of $\mathrm{FC}_{\mathrm{p} 0.38}$ for El Niño months (top quartile of Niño-3.4), La Niña months (bottom quartile of Niño-3.4), and neutral months (middle half of Niño-3.4). It is clear that the histogram shifts to greater fractional coverage values (Fig. 2c) during both phases of ENSO. For ocean-only (Figs. 2df), as compared to the entire tropical domain, the rela- 

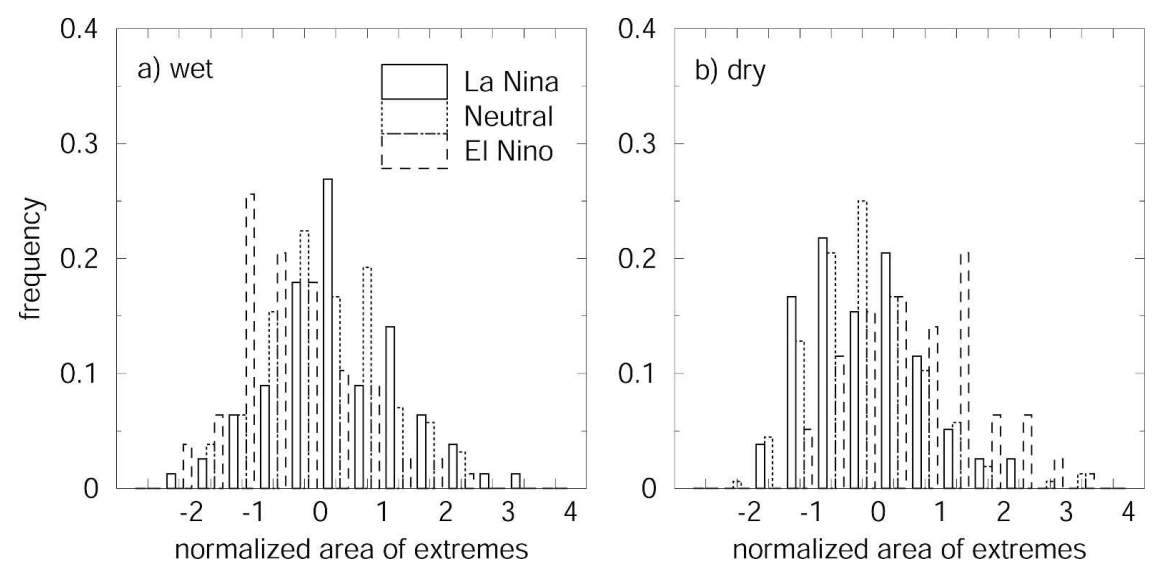

FIG. 3. Same as in Fig. 2i, except divided into (a) wet and (b) dry extremes.

tionship between positive Niño-3.4 values and precipitation extremes improves for wet months (from $r_{\mathrm{El}}=0.41$ to $\left.r_{\mathrm{El}}=0.54\right)$ and degrades slightly for dry months (from $r_{\mathrm{El}}=0.67$ to $r_{\mathrm{El}}=0.62$ ). By restricting to ocean-only the relationship between negative Niño-3.4 values and precipitation extremes is slightly worse for wet months (from $r_{\mathrm{La}}=-0.28$ to $r_{\mathrm{La}}=-0.23$ ), and slightly better for dry months (from $r_{\mathrm{La}}=-0.26$ to $\left.r_{\mathrm{La}}=-0.30\right)$. The frequency distribution of $\mathrm{FC}_{\mathrm{p} 0.38}$ over ocean shows the same shift toward larger values for El Niño and La Niña (Fig. 2f). When examining land only, the relationship between ENSO and frequency of monthly precipitation extremes becomes more complicated. As Niño-3.4 becomes more negative, the frequency of wet extremes shows a similar increase over land (Fig. 2g) as was seen over ocean (Fig. $2 \mathrm{~d}$ ); however, there is no relationship with frequency of dry extremes (Fig. 2h). As Niño-3.4 becomes more positive there is an increase (decrease) in frequency of dry (wet) extremes (Figs. 2g,h), consistent with Lyon and Barnston (2005). El Niño's contrasting relationship between the frequency of wet and dry extremes results in only a weak enhancement of the integrated coverage of extremes as compared to neutral (Fig. 2i).

Figure 3 shows the frequency distribution of $\mathrm{FC}_{\mathrm{p} 0.38}$ over land (Fig. 2i) separately for wet and dry extremes. The El Niño histogram is shifted to lower fractional coverage values for wet extremes and higher fractional coverage values for dry extremes. In both cases the distributions are significantly different, greater than the $0.1 \%$ level, from the La Niña and neutral distributions according to a Kolmogorov-Smirnov test. A few large El Niño events account for this shift in the distribution. The June to May average of normalized fractional coverages of dry extremes was greatest during the 1982/83 (1.34), 1991/92 (1.18), and 1997/98 (1.51) El Niños, and the normalized fractional coverages of wet extremes was smallest during the 1991/92 (-1.06) and 1997/98 $(-0.61)$ El Niños.

\section{b. Daily precipitation extremes}

Monthly averages are insufficient to quantify intense rainfall events, which may last hours to a few days. However, the short record of hourly to daily rainfall over the globe from TRMM and other high-resolution precipitation products limits an interannual analysis. In fact, only 3 El Niños (1997/98, 2002/03, 2004/05) and one extended La Niña (1998-2001) were at least partially observed by TRMM during the period of record. Thus, to make more general inferences about the relationship between daily extreme precipitation frequency and ENSO over the globe, we combined the resolution and accuracy of TMPA at the daily scale with the length of record from GPCP (Fig. 4).

First, to help answer the question, "Are heavy rainfall days more frequent during ENSO over the 8-year TRMM record?" (Fig. 4), the statistically significant relationships between extreme daily precipitation frequency and Niño-3.4 are plotted in Figs. 5b, 5d, 5f, and $5 \mathrm{~h}$. This is compared with the statistically significant relationships between seasonal rainfall and Niño-3.4 in Figs. 5a, 5c, 5e, and 5g. Even with the short TRMM record, the well-known ENSO-related precipitation anomalies (e.g., Ropelewski and Halpert 1987; Dai and Wigley 2000; Curtis and Adler 2003) are apparent in both seasonal rainfall, consistent with other studies using TRMM (e.g., Adler et al. 2000; Adler et al. 2003b; Haddad et al. 2004), and in extreme daily precipitation frequency, suggesting a strong spatial correlation. The percent coverage of significant Kendall's $\tau$ values between mean rainfall and ENSO is similar to the percent coverage of significant Kendall's $\tau$ values between extreme daily precipitation frequency and ENSO (Table 2). The coverage is a maximum in JFM and OND, at 


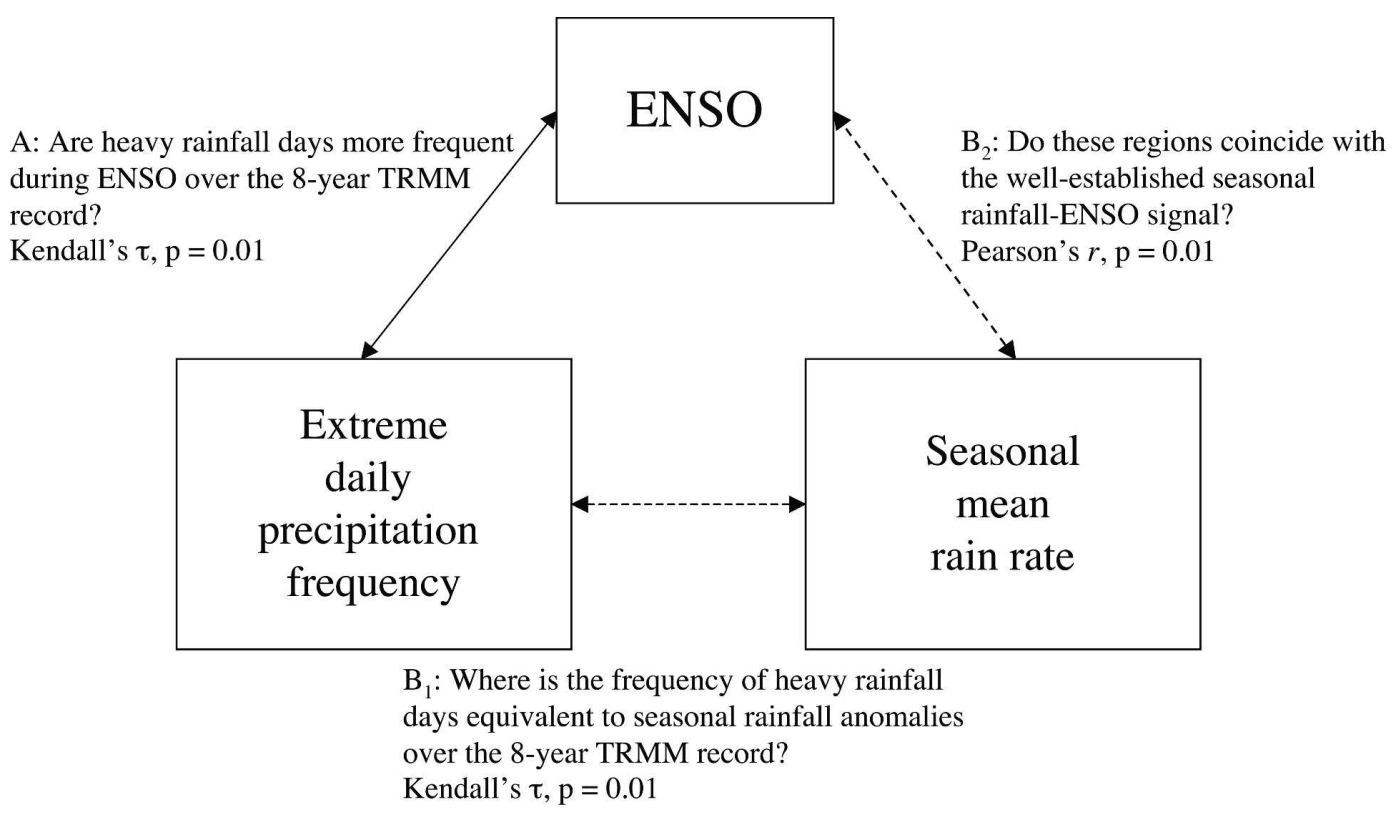

FIG. 4. Methodological framework for using both GPCP and TRMM precipitation data to help determine the relationship between extreme precipitation frequency and ENSO. Three relational questions are posed. Positive answers are determined by the statistical test and significance level given.

the peak of a canonical ENSO event (Rasmusson and Carpenter 1982). Thus, the global coverage of extremes appears to be tied to the seasonal evolution of SST. To determine if the density of colored areas shown in Fig. 5 could be produced by chance, a Monte Carlo significance test was performed by randomly shuffling the Niño-3.4 time series. In every case, except extreme precipitation days in AMJ over the ocean, the significance is greater than the $10 \%$ level $(p=0.10)$, and in the majority of cases the significance exceeds the $0.1 \%$ level $(p \leq 0.001)$. The lowest significance levels all occur in AMJ when the global ENSO signal is the weakest.

The spatial correspondence in Fig. 5 implies that extreme daily precipitation frequency is strongly related to seasonal rainfall in many areas of the globe. Thus, to extend the short daily precipitation dataset by using the longer monthly data, we ask the following two questions: "Where is the frequency of heavy rainfall days equivalent to seasonal rainfall anomalies over the 8 -year TRMM record?" and "Do these regions coincide with the well-established seasonal rainfall-ENSO signal?" (Fig. 4). In that way, positive seasonal rainfall anomalies serve as a proxy for an increase in extreme daily precipitation frequency.

Kendall $\tau$ was computed between extreme daily precipitation frequency and seasonal mean rainfall, and found to be predominantly positive. Figure 6 shows those values that exceed the $1 \%$ significance test. Most of the globe is covered, with the highest significances occurring over the oceans. In addition, correlations significant at the 1\% level between GPCP seasonal rainfall and Niño-3.4 from 1979 to 2005 overlay the TRMMbased data (Fig. 6). The intersection of these two fields suggests areas where extreme daily precipitation frequency is a good indicator for seasonal precipitation and where seasonal precipitation is well related to ENSO. To compare the two fields at the same scale, the percent area of each $2.5^{\circ}$ grid block with significant GPCP-ENSO correlations where extreme precipitation frequency is significantly related to mean rain rate (at the $0.25^{\circ}$ scale) was computed and plotted in Fig. 7. The contours of Fig. 6 are repeated to distinguish extreme events as being either associated with El Niño or La Niña events. Thus, Fig. 7 provides additional information to the well-known seasonal rainfall-ENSO relationships, as contoured regions containing higher percent values can be thought of as being more likely to experience an increase in extreme events. Positive precipitation anomalies in tropical oceanic regions, especially from October to March, are dominated by extreme events (Fig. 7). Land areas show a weaker relationship, for example the Gulf of Mexico-southeast United States in JFM and northeast Brazil in JFM and AMJ. The land area that seems to be most affected by an increase in extreme events is the Maritime Continent during La Niña. The Philippines are covered by high percentages in JFM, the equatorial Maritime Con- 

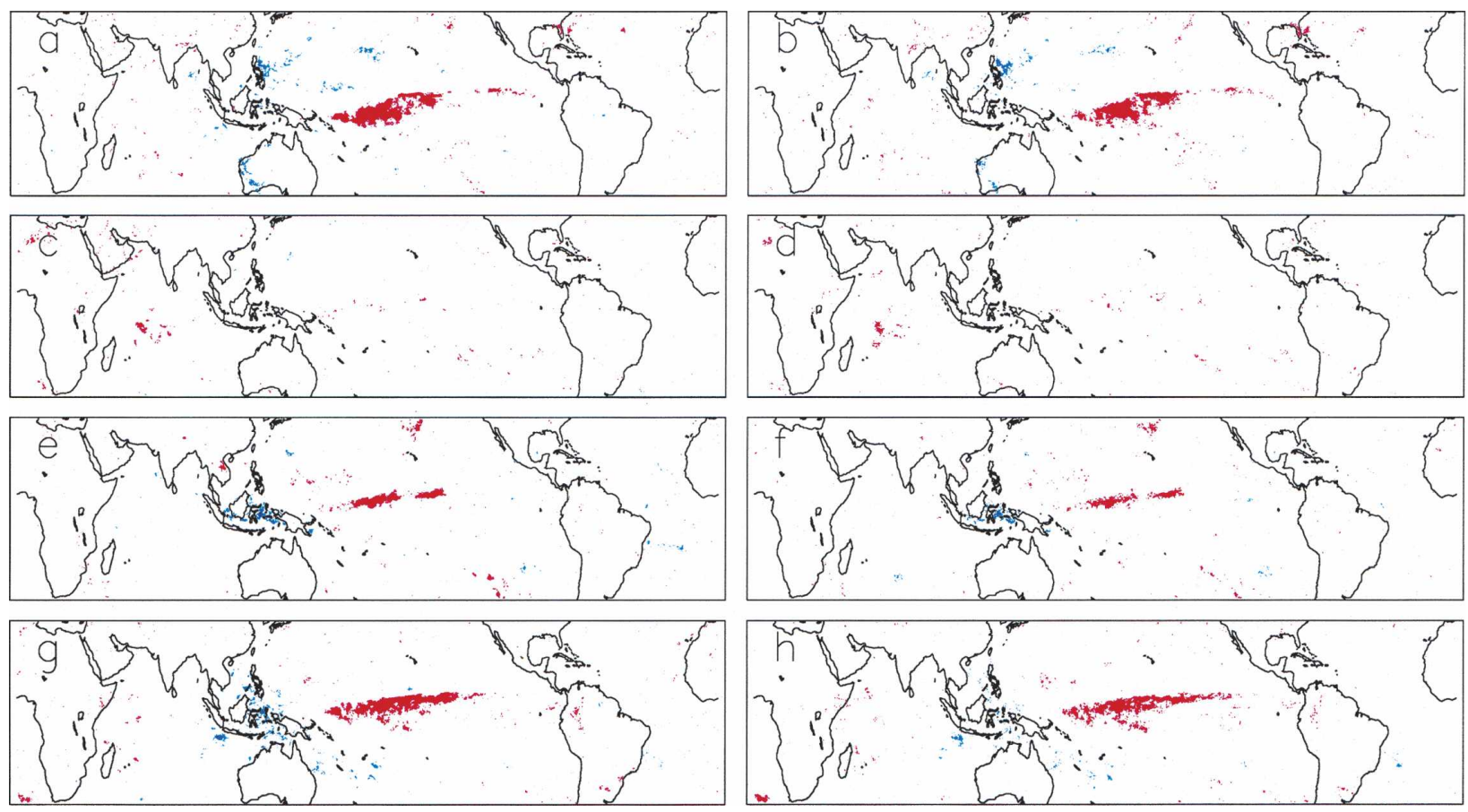

FIG. 5. One percent significance level of Kendall's $\tau$ test between seasonally normalized Niño-3.4 and (a), (c), (e), (g) mean rainfall and (b), (d), (f), (h) extreme precipitation frequency for the TRMM record (1998-2005). Seasons are January-March in (a), (b), April-June in (c), (d), July-September in (e), (f), and October-December in (g), (h). Positive (negative) relationships are shown in red (blue).

tinent in JAS, and the coast of Australia in OND. During El Niño, only a few $2.5^{\circ}$ grid blocks over land have percentages over 75 .

Finally, the global tropical $\left(25^{\circ} \mathrm{N}-25^{\circ} \mathrm{S}\right)$ areaweighted average of the number of extreme precipitation days for each season was computed. The TRMM time series was normalized and plotted in Fig. 1b (closed circles) to compare with the GPCP analysis. Just like the frequency of monthly precipitation extremes, the number of daily precipitation extremes per season increases with ENSO. Both show significant correlations for the 1998-2004 period. The GPCP-based $\mathrm{FC}_{\mathrm{p} 0.38}$ is correlated with the absolute value of normalized Niño-3.4 at 0.65 (up from 0.61 for the entire 27-yr record), and the number of TMPA daily precipitation extremes is correlated to the 3-month average of the absolute value of normalized Niño-3.4 at 0.67.

\section{Discussion and conclusions}

While seasonal precipitation is known to undergo strong variability in relation to ENSO globally, there is a gap in our understanding of how the characteristics of extreme precipitation change with the tropical climate phenomenon, especially over the oceans. With this motivation, the spatial extent of percentile-defined thresholds of monthly and daily precipitation extremes estimated from TRMM and GPCP were examined in rela-

TABLE 2. Fractional coverage of significant Kendall's $\tau$ values $(p=0.01)$ between normalized Niño-3.4 and 1$)$ mean rain rate and 2) extreme precipitation frequency by quarter for 1998-2005. The $p$ value denotes the significance of the fractional coverage as determined by Monte Carlo experiment.

\begin{tabular}{lccccc}
\hline \hline & 1998-2005 & JFM & AMJ & JAS & OND \\
\hline 1) Mean rain rate & Ocean & $0.157(p \leq 0.001)$ & $0.078(p=0.060)$ & $0.121(p \leq 0.001)$ & $0.142(p \leq 0.001)$ \\
& Land & $0.096(p=0.006)$ & $0.074(p=0.082)$ & $0.070(p=0.032)$ & $0.095(p \leq 0.001)$ \\
& Total & $0.141(p \leq 0.001)$ & $0.077(p=0.034)$ & $0.107(p \leq 0.001)$ & $0.129(p \leq 0.001)$ \\
2) Extreme precipitation days (wet) $)$ & Ocean & $0.116(p \leq 0.001)$ & $0.063(p=0.134)$ & $0.096(p \leq 0.001)$ & $0.107(p \leq 0.001)$ \\
& Land & $0.078(p=0.027)$ & $0.067(p=0.075)$ & $0.074(p \leq 0.001)$ & $0.083(p=0.011)$ \\
& Total & $0.106(p \leq 0.001)$ & $0.064(p=0.083)$ & $0.090(p \leq 0.001)$ & $0.101(p \leq 0.001)$ \\
\hline
\end{tabular}



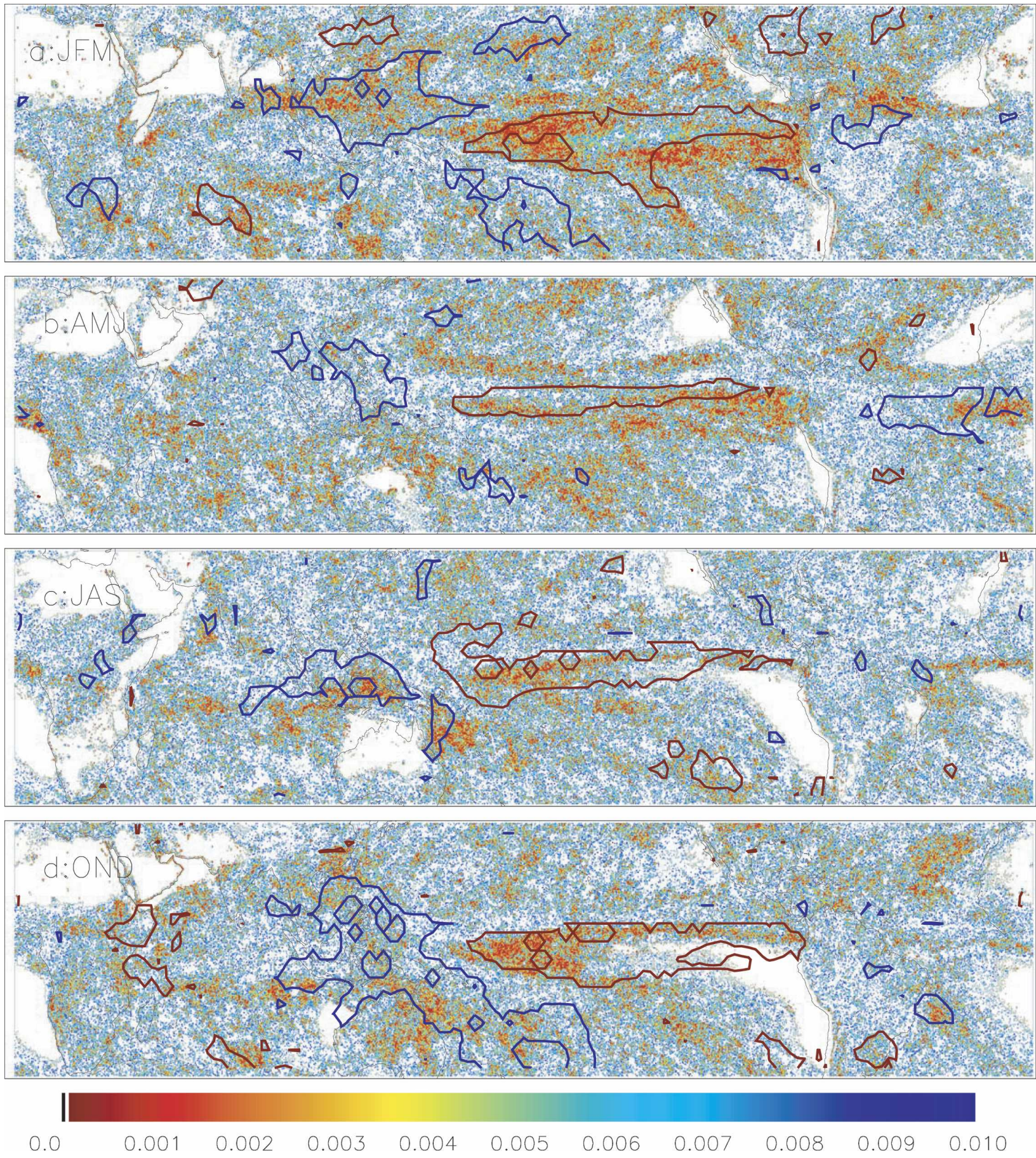

FIG. 6. The relationship between extreme precipitation frequency and mean rain rate over the TRMM record, and ENSO and mean rain rate over the GPCP record. Colors denote Kendall's $\tau$ significance levels between mean rain rate and extreme precipitation $(p \leq$ 0.01). Dark red (blue) contours show areas of positive (negative) correlation significant at the $1 \%$ level between seasonal rainfall and Niño-3.4 from 1979 to 2005. Seasons are (a) JFM, (b) AMJ, (c) JAS, and (d) OND.

tion to ENSO. Given the added surface heat content of the Pacific during El Niño, it may not be surprising to find an increase in extreme wet areas over the tropical oceans, with the opposite (dry) conditions during La
Niña. However, from 1979 to 2004 the relationship between the oceanic area of extreme dry months and El Niño was the strongest. Much of the tropical Atlantic and waters surrounding the Maritime Continent expe- 

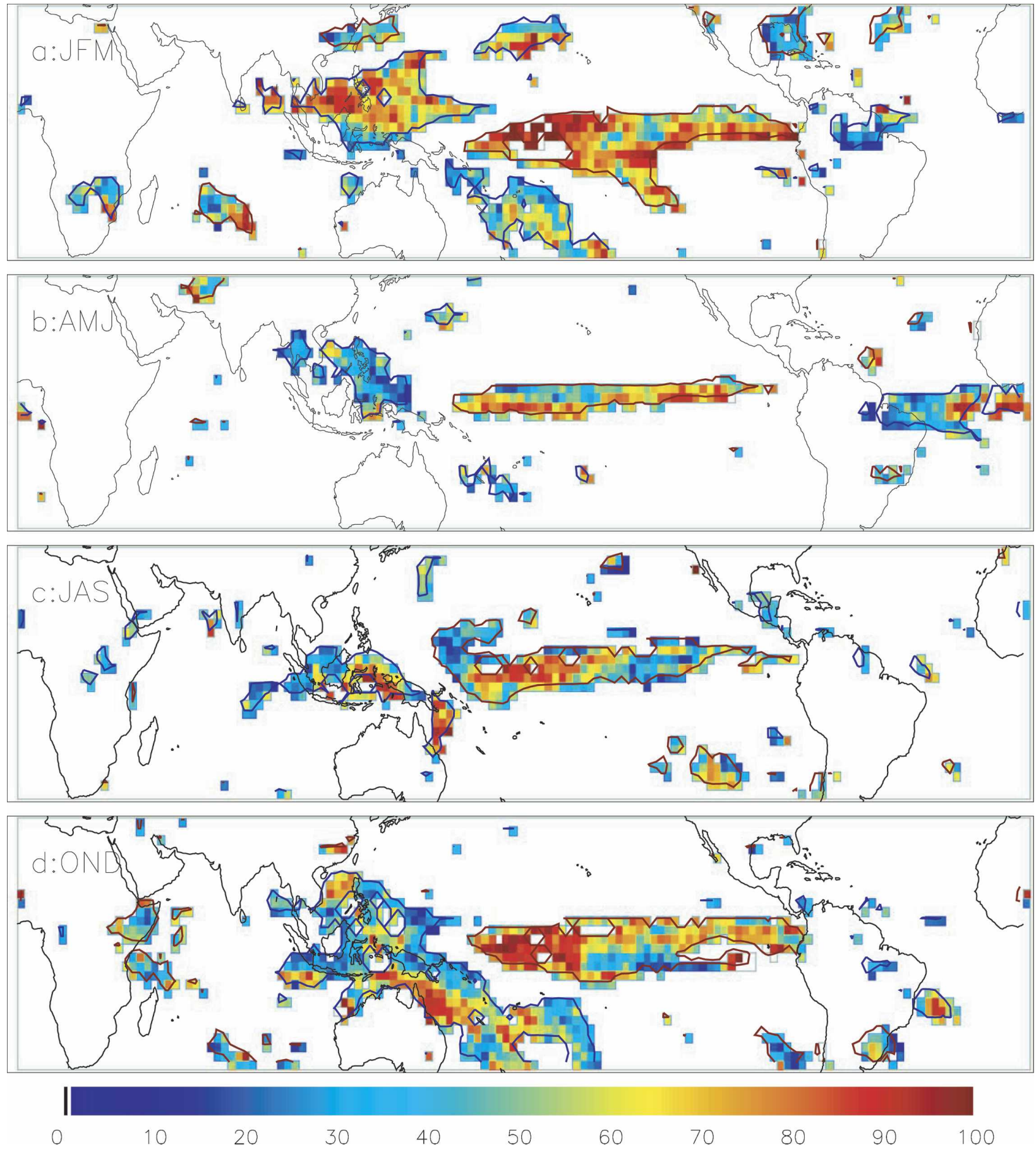

FIG. 7. Percent area of $2.5^{\circ}$ grid blocks with significant GPCP-ENSO correlations, where extreme precipitation frequency is significantly related to mean rain rate (see Fig. 6). Color bar denotes the percentage level. As in Fig. 6, dark red (blue) contours show areas of positive (negative) correlation significant at the 1\% level between seasonal rainfall and Niño-3.4 from 1979 to 2005 . Seasons are (a) JFM, (b) AMJ, (c) JAS, and (d) OND.

rience extreme dryness during El Niño, and furthermore lack of rainfall is better described at the monthly scale than intense rain events. During El Niño the fraction of land covered by extremes increases for the dry end and decreases for the wet end. During La Niña the fraction of land covered by wet extremes increases, while there is no change in dry extremes. Thus, because of the juxtaposition of tropical land areas with the as- 
cending branches of the global Walker Circulation, El Niños (La Niñas) lead to generally dry (wet) conditions over land.

Wet extremes are better described at the daily to hourly time scale. Extreme daily precipitation frequency was defined with the daily average of TMPA. As with monthly extremes, the number of daily extremes since 1998 increased over the Tropics during seasons of strong El Niño and La Niña. The spatial relationship between extreme daily precipitation frequency and ENSO mirrors the seasonal rainfall-ENSO relationship because of the strong interdependence between seasonal precipitation and the number of very large rain events. With this background, the relationship between seasonal rainfall from GPCP and ENSO (e.g., Curtis and Adler 2003) can be reexamined to identify areas where extreme daily precipitation frequency was almost certain to have changed substantially with past ENSO events, and must be carefully monitored in future ENSO events. Seasonal precipitation over land appears to be much less affected by extreme events than over ocean, especially during El Niño. However, during La Niña the following regions are likely to experience an increased number of extreme daily precipitation events: the Philippines in January-March, the interior Maritime Continent in July-September, and the northwest coast of Australia October-December.

The Philippines example is poignant, considering the days of heavy rainfall that led to a landslide, burying the rural town of Guinsaugon on 17 February 2006. To further this analysis and hopefully mitigate future tragedies from occurring, it is necessary to establish and maintain hourly to daily rain gauge networks in the aforementioned regions. Australia has a dense daily rainfall dataset, which is currently being used to validate TRMM and other high-resolution precipitation products. Future work will include examining these rain gauges over a much longer time period to confirm the results from TRMM and GPCP.

This study contributes to our understanding of the variability of extreme precipitation over the globe in relation to the earth's most significant climate phenomenon: ENSO. However, more work is needed to advance the findings here. To capture short-lived extreme events, we intend to repeat the daily analysis using the full 3-hourly TMPA product. Also, while a local definition of extreme precipitation is important over land (e.g., water management), and related to atmospheric circulation anomalies, rain rates exceeding critical values have direct implications on local hydrology. Thus, an equally important definition would be a fixed threshold value, where rainfall in excess of the value would be considered extreme. Preliminary work suggests that the frequency of daily rain rates in excess of 25 and $50 \mathrm{~mm}$ day $^{-1}$ over both ocean and land show a similarly significant relationship with ENSO as the percentile analysis.

Acknowledgments. This paper is based on "Precipitation extremes with GPCP and TRMM," presented on 24 June 2005 at the Fifth International Science Conference on the Global Energy and Water Cycle in Costa Mesa, California. The work is funded by a grant from NASA's Energy and Water Cycle Study (NEWS). The authors wish to thank three anonymous reviewers and Dr. Phil Arkin for their comments, which improved an earlier version of this manuscript.

\section{REFERENCES}

Adler, R. F., G. J. Huffman, D. T. Bolvin, S. Curtis, and E. J. Nelkin, 2000: Tropical rainfall distributions determined using TRMM combined with other satellite and rain gauge information. J. Appl. Meteor., 39, 2007-2023.

_ , and Coauthors, 2003a: The version-2 Global Precipitation Climatology Project (GPCP) monthly precipitation analysis (1979-present). J. Hydrometeor., 4, 1147-1167.

— C. Kummerow, D. Bolvin, S. Curtis, and C. Kidd, 2003b: Status of TRMM monthly estimates of tropical precipitation. Cloud Systems, Hurricanes, and the Tropical Rainfall Measuring Mission (TRMM), Meteor. Monogr., No. 51, Amer. Meteor. Soc., 223-234.

Bartlett, M. S., 1935: Some aspects of the time-correlation problem in regard to tests of significance. J. Roy. Stat. Soc., 98A, 536-543.

Carvalho, L. M. V., C. Jones, and B. Liebmann, 2002: Extreme precipitation events in southeastern South America and large-scale convective patterns in the South Atlantic convergence zone. J. Climate, 15, 2377-2394.

,-- , and — 2004: The South Atlantic convergence zone: Intensity, form, persistence, and relationships with intraseasonal to interannual activity and extreme rainfall. J. Climate, 17, 88-108.

Cavazos, T., and D. Rivas, 2004: Variability of extreme precipitation events in Tijuana, Mexico. Climate Res., 25, 229-242.

Curtis, S., and R. F. Adler, 2003: Evolution of El Niñoprecipitation relationships from satellites and gauges. J. Geophys. Res., 108, 4153, doi:10.1029/2002JD002690.

,-- G. J. Huffman, G. Gu, D. T. Bolvin, and E. J. Nelkin, 2006: Comments on "El Niño: Catastrophe or opportunity." J. Climate, 19, 6439-6442.

Dai, A., and T. M. L. Wigley, 2000: Global patterns of ENSOinduced precipitation. Geophys. Res. Lett., 27, 1283-1286.

, I. Y. Fung, and A. D. Del Genio, 1997: Surface observed global land precipitation variations during 1900-88. J. Climate, 10, 2943-2962.

Easterling, D. R., J. L. Evans, P. Ya. Groisman, T. R. Karl, K. E. Kunkel, and P. Ambenje, 2000: Observed variability and trends in extreme climate events: A brief review. Bull. Amer. Meteor. Soc., 81, 417-425.

Fauchereau, N., S. Trzaska, M. Rouault, and Y. Richard, 2003: Rainfall variability and changes in Southern Africa during 
the 20th century in the global warming context. Nat. Hazards, 29, 139-154.

Gershunov, A., and T. P. Barnett, 1998: ENSO influence on intraseasonal extreme rainfall and temperature frequencies in the contiguous United States: Observations and model results. J. Climate, 11, 1575-1586.

— and D. R. Cayan, 2003: Heavy daily precipitation frequency over the contiguous United States: Sources of climatic variability and seasonal predictability. J. Climate, 16, 2752-2765.

Goddard, L., and M. Dilley, 2005: El Niño: Catastrophe or opportunity. J. Climate, 18, 651-665.

Gu, G., R. F. Adler, G. J. Huffman, and S. Curtis, 2007: Tropical rainfall variability on interannual-to-interdecadal and longer time scales derived from the GPCP monthly product. $\mathrm{J}$. Climate, 20, 4033-4046.

Haddad, Z. S., J. P. Meagher, R. F. Adler, E. A. Smith, and S. L. Durden, 2004: Global variability of precipitation according to the Tropical Rainfall Measuring Mission. J. Geophys. Res., 109, D17103, doi:10.1029/2004JD004607.

Haylock, M. R., and Coauthors, 2006: Trends in total and extreme South American rainfall in 1960-2000 and links with sea surface temperature. J. Climate, 19, 1490-1512.

Houghton, J. T., Y. Ding, D. J. Griggs, M. Noguer, P. J. van der Linden, X. Dai, K. Maskell, and C. A. Johnson, Eds., 2001: Climate Change 2001: The Scientific Basis. Cambridge University Press, $881 \mathrm{pp}$.

Huffman, G. J., R. F. Adler, M. Morrissey, D. T. Bolvin, S. Curtis, R. Joyce, B. McGavock, and J. Susskind, 2001: Global precipitation at one-degree daily resolution from multisatellite observations. J. Hydrometeor., 2, 36-50.

, 一 , D. T. Bolvin, G. Gu, E. J. Nelkin, K. P. Bowman, E. F. Stocker, and D. B. Wolff, 2007: The TRMM multisatellite precipitation analysis (TMPA): Quasi-global, multiyear, combined-sensor precipitation estimates at fine scale. J. $\mathrm{Hy}$ drometeor., 8, 38-55.

Katz, R. W., and B. G. Brown, 1992: Extreme events in a changing climate: Variability is more important than averages. Climatic Change, 21, 289-302.

Kharin, V. V., and F. W. Zwiers, 2000: Changes in extremes in an ensemble of transient climate simulations with a coupled atmosphere-ocean GCM. J. Climate, 13, 3760-3788.

L'Heureux, M. L., M. E. Mann, B. I. Cook, B. E. Gleason, and R. S. Vose, 2004: Atmospheric circulation influences on sea- sonal precipitation patterns in Alaska during the latter 20th century. J. Geophys. Res., 109, D06106, doi:10.1029/ 2003JD003845.

Liebmann, B., C. Jones, and L. M. V. Carvalho, 2001: Interannual variability of daily extreme precipitation events in the state of Sao Paulo, Brazil. J. Climate, 14, 208-218.

Lyon, B., and A. G. Barnston, 2005: ENSO and the spatial extent of interannual precipitation extremes in tropical land areas. $J$. Climate, 18, 5095-5109.

Nicholls, N., and W. Murray, 1999: Workshop on indices and indicators for climate extremes: Asheville, NC, USA, 3-6 June 1997 Breakout Group B: Precipitation. Climatic Change, 42, 23-29.

Rasmusson, E. M., and T. H. Carpenter, 1982: Variations in tropical sea surface temperature and surface wind fields associated with the Southern Oscillation/El Niño. Mon. Wea. Rev., 111, 517-528.

Ropelewski, C. F., and M. S. Halpert, 1987: Global and regional scale precipitation patterns associated with the El Niño/ Southern Oscillation. Mon. Wea. Rev., 115, 1606-1626.

— , and _ 1989: Precipitation patterns associated with the high index phase of the Southern Oscillation. J. Climate, 2, 268-284.

Stewart, R., 2005: A focus on extremes in GEWEX. GEWEX News, Vol. 15, No. 2, International GEWEX Project Office, Silver Spring, MD, 5.

Trenberth, K. E., 1997: The definition of El Niño. Bull. Amer. Meteor. Soc., 78, 2771-2777.

Wilheit, T., A. Chang, and L. Chiu, 1991: Retrival of monthly rainfall indices from microwave radiometric measurements using probability distribution function. J. Atmos. Oceanic Technol., 8, 118-136.

Xie, P., and P. A. Arkin, 1998: Global monthly precipitation estimates from satellite-observed outgoing longwave radiation. J. Climate, 11, 137-164.

—, J. E. Janowiak, P. A. Arkin, R. Adler, A. Gruber, R. Ferraro, G. J. Huffman, and S. Curtis, 2003: GPCP pentad precipitation analyses: An experimental dataset based on gauge observations and satellite estimates. J. Climate, 16, 21972214.

Zipser, E. J., D. J. Cecil, C. Liu, S. W. Nesbitt, and D. P. Yorty, 2006: Where are the most intense thunderstorms on Earth? Bull. Amer. Meteor. Soc., 87, 1057-1071. 
Copyright of Journal of Hydrometeorology is the property of American Meteorological Society and its content may not be copied or emailed to multiple sites or posted to a listserv without the copyright holder's express written permission. However, users may print, download, or email articles for individual use. 